\title{
The sick leave policy conundrum
}

I paid sick leave a safety net or an earned entitlement? Seems like a simple question, yet it will be a much-debated one in Canada next year.

The federal government recently confirmed its plan to overhaul sick leave policy for the public sector in 2014 to reduce what it claims is an alarming rate of absenteeism and lost productivity. The story has played out in newspapers as a forthcoming battle between costcutting politicians and benefitpreserving federal unions. But what does research tell us about the effects of sick leave policies on employee behaviour?

"Research shows, very clearly, that one of the biggest predictors of volume of absence is company policy. Any organization that has a more generous provision for absenteeism will get it," says Gary Johns, a professor in the Department of

Management at the John Molson School of Business, Concordia University, in Montréal, Quebec. "On the other side of the coin, there is research showing that what you might call draconian attendance management policies have been associated with presenteeism, or going to work ill."

Though absenteeism tends to receive the most attention from employers, presenteeism is a legitimate problem and worthy of more investigation, Johns noted in a paper ( $\mathrm{J}$ Occup Health Psychol 2011;16:483:500). Of particular interest, suggests Johns, is how going to work sick affects productivity. There are also other consequences to showing up at the office with an acute illness such as influenza, including possibly infecting coworkers and delayed recovery from illness.

"Going to work while ill, commonly called presenteeism, has important implications for employee wellbeing, employing organizations and theory in the domain of attendance at work," wrote Johns.

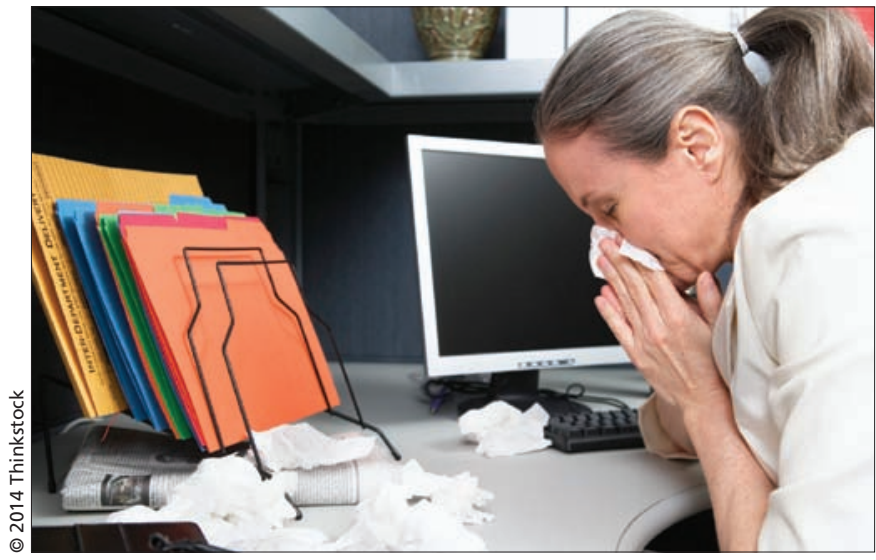

Employees without paid sick days are more likely to be in the office when ill, possibly infecting coworkers.
The perfect sick leave policy would discourage abuse - the proverbial sick day on the golf course - while encouraging employees with legitimate illnesses to stay home and recover, with special provisions for long-term disability. Unfortunately, no policy can sick leave policies," says Eileen Appelbaum, a senior economist with the Center for Economic and Policy Research in Washington, DC. "Forty percent of our population does not have even one paid sick day."

In Canada, the government's main concern seems to be that public servants, who receive 15 paid sick days a year, can accumulate unused days indefinitely, and this banked time is often regarded with a use-it-or-lose-it mentality. As a result, absenteeism rates are 2.5 times higher than in the private sector, according to Treasury Board President Tony Clement.

Federal unions, however, have challenged that notion and claim that work environments differ in the private and public sectors, so direct comparisons aren't valid.

Large attempts to reform sick leave guarantee the desired outcomes for all employees.

"The balance is difficult to achieve, because employees tend to utilize the benefits they have been granted," says Johns.

Many countries have grappled with this sick leave conundrum. Rates of absenteeism vary widely across the world, from highs of 26-29 days a year in Slovakia and Sweden to lows of 4-5 days a year in the United States and Greece (J Public Econ 2010;94:110822). Are citizens of Spain (18.6 days) really getting sick three times as often as people in the United Kingdom (7.2 days)?

Not likely, scholars in this area suggest, so there are other factors at play. A major one is how much people stand to lose financially when they call in sick. The reason absenteeism rates are so low in the US, for example, is that staying home to nurse a flu or cold is simply too costly for many people.

"In the US, in the private sector, we have very little in the way of generous policies have been attempted before. In 1996, Germany reduced sick pay from $100 \%$ of wages to $80 \%$ for the first six weeks of illness. The change resulted in a two-day reduction in annual work absences and no perceptible changes to citizens' health outcomes ( $\mathrm{J}$ Health Econ 2010;29:285-302).

"It also led to a reduction of almost half a day in the length of hospital stays," says Patrick Puhani, the paper's lead author and a professor of labour economics at Leibniz Universität Hannover in Germany. "What we found was that, in essence, doctors had incentives to keep people in hospitals, and patients didn't mind as much when they didn't lose money."

The law did not sit well with German trade unions, though, and many launched lawsuits. In 1999, following the election of a new government, the sick leave reform was repealed. Roger Collier, CMAJ

CMAJ 2014. DOI:10.1503/cmaj.109-4660 